Article

\title{
Supplementation with Red Wine Extract Increases Insulin Sensitivity and Peripheral Blood Mononuclear Sirt1 Expression in Nondiabetic Humans
}

\author{
Munehiro Kitada ${ }^{1,2, *(\mathbb{D} \text {, } \text {, Yoshio Ogura }}{ }^{1}$, Itaru Monno ${ }^{1}$ and Daisuke Koya ${ }^{1,2, * \mathbb{C}}$ \\ 1 Department of Diabetology and Endocrinology, Kanazawa Medical University, Daigaku, Uchinada, \\ Ishikawa 920-0293, Japan; namu1192@kanazawa-med.ac.jp (Y.O.); imonno@kanazawa-med.ac.jp (I.M.) \\ 2 Division of Anticipatory Molecular Food Science and Technology, Medical Research Institute, \\ Kanazawa Medical University, Daigaku, Uchinada, Ishikawa 920-0293, Japan \\ * Correspondence: kitta@kanazawa-med.ac.jp (M.K.); koya0516@kanazawa-med.ac.jp (D.K.); \\ Tel.: +81-76-286-2211 (M.K. \& D.K.); Fax: +81-76-286-6927 (M.K. \& D.K.)
}

Received: 22 August 2020; Accepted: 9 October 2020; Published: 12 October 2020

check for updates

\begin{abstract}
The aim of this study was to investigate the effects of dietary supplementation with a nonalcoholic red wine extract (RWE), including resveratrol and polyphenols, on insulin sensitivity and Sirt1 expression in nondiabetic humans. The present study was a single-arm, open-label and prospective study. Twelve subjects received supplementation with RWE, including $19.2 \mathrm{mg}$ resveratrol and $136 \mathrm{mg}$ polyphenols, daily for 8 weeks. After 8 weeks, metabolic parameters, including glucose/lipid metabolism and inflammatory markers, were evaluated. mRNA expression of Sirt1 was evaluated in isolated peripheral blood mononuclear cells (PBMNCs). Additionally, Sirt1 and phosphorylated AMP-activated kinase (p-AMPK) expression were evaluated in cultured human monocytes (THP-1 cells). Supplementation with RWE for 8 weeks decreased the homeostasis model assessment for insulin resistance (HOMA-IR), which indicates an increase in insulin sensitivity. Serum low-density lipoprotein-cholesterol (LDL-C), triglyceride (TG) and interleukin-6 (IL-6) were significantly decreased by RWE supplementation for 8 weeks. Additionally, Sirt1 mRNA expression in isolated PBMNCs was significantly increased after 8 weeks of RWE supplementation. Moreover, the rate of increase in Sirt1 expression was positively correlated with the rate of change in HOMA-IR. The administration of RWE increased Sirt1 and p-AMPK expression in cultured THP-1 cells. Supplementation with RWE improved metabolism, such as insulin sensitivity, lipid profile and inflammation, in humans. Additionally, RWE supplementation induced an increase in Sirt1 expression in PBMNCs, which may be associated with an improvement in insulin sensitivity.
\end{abstract}

Keywords: red wine extract; resveratrol; polyphenols; insulin sensitivity; Sirt1

\section{Introduction}

Metabolic derangement, including type 2 diabetes mellitus (T2DM), hypertension and dyslipidemia, which is based on insulin resistance, is closely related to the initiation and progression of cardiovascular disease (CVD) [1]. Therefore, maintaining metabolic health, including improving insulin sensitivity, is important to protect vascular tissues against metabolic-derangement-related cellular damage. Individual lifestyles, including dietary habits, affect metabolic and cardiovascular health. Appropriate consumption of red wine, 20-30 g/day as amount of alcohol, is thought to be part of a healthy lifestyle [2-4]. Previous epidemiological studies have shown an inverse association between dietary polyphenol consumption and mortality from CVD [5-8]. The components of red wine contain 
many polyphenols, which are a complex mixture of flavonoids such as anthocyanins and flavan-3-ols and nonflavonoids such as resveratrol, cinnamates and gallic acid [9]. Red wine polyphenols possess vasoprotective effects through anti-aggregatory platelet activity, antioxidant and anti-inflammatory properties, the generation and release of nitric oxide (NO) and glucose/lipid-metabolism-improving effects, which contribute to maintaining metabolic and cardiovascular health [10-12].

Aging is closely associated with metabolic derangement, including insulin resistance. Caloric restriction (CR)/dietary restriction (DR) retards aging or extends life spans [13]. The benefits of CR/DR for the suppression of age-related disorders, including glucose intolerance and CVD, have also been reported in rhesus monkeys and humans by improving insulin sensitivity and oxidative stress/inflammation [14-17]. Therefore, CR/DR mimetics may be anti-aging therapies, resulting in the maintenance of cardiometabolic health. Sirt1, a nicotinamide adenine dinucleotide (NAD ${ }^{+}$)-dependent deacetylase, has been identified as one of the possible molecules through which CR/DR exerts anti-aging effects [18,19]. Resveratrol, a polyphenolic phytoalexin that occurs in red wine, has been one of the most extensively studied Sirt1 activators, as one of the CR/DR mimetics [20] and is a critical constituent that contributes to the health benefits of red wine. Thus, polyphenols, including resveratrol from red wine, may be candidates to improve cardiometabolic alterations associated with aging due to their pleiotropic properties. However, there are few reports on whether red wine polyphenols, exert beneficial effects on glucose/lipid metabolism and Sirt1 activation in humans. In this study, we investigated the effects of red wine polyphenols on glucose/lipid metabolism and Sirt1 expression in isolated peripheral blood mononuclear cells (PBMNCs) using red wine extract (RWE).

\section{Materials and Methods}

\subsection{Composition of $R W E$}

The alcohol-free RWE was obtained from NATURE Supplement (Osaka, Japan). This RWE is derived from red wine produced in the Rhone valley regions of southern France. The polyphenol contents in the RWE were assessed by high-performance liquid chromatography (HPLC) analysis (Figure S1) and revealed that $166 \mathrm{mg}$ of wine solids contained $9.6 \mathrm{mg}$ of resveratrol and $68 \mathrm{mg}$ of polyphenols: catechin $1.16 \mathrm{mg}$, epicatechin $0.83 \mathrm{mg}$, tannin $29.3 \mathrm{mg}$, quercetin glycoside $0.33 \mathrm{mg}$, malvidin glycoside $1.99 \mathrm{mg}$, total anthocyanin $5.15 \mathrm{mg}$, anthocyanin monomer $4.15 \mathrm{mg}$, anthocyanin polymer $1.00 \mathrm{mg}$ per 1 capsule.

\subsection{Subjects and Study Design}

Participants were recruited through advertisements on local posters. Males or females who were 20-70 years old were eligible. The exclusion criteria included diabetes $(\mathrm{HbA} 1 \mathrm{c} \geq 6.5 \%)$; pre-existing endocrine, kidney, liver, heart and malignant disease; anemia (male: hemoglobin $(\mathrm{Hb})<10.0 \mathrm{~g} / \mathrm{dL}$, female: $\mathrm{Hb}<9.0 \mathrm{~g} / \mathrm{dL}$ ); alcohol abuse; smoking; the use of medicines/supplements; and planned lifestyle changes. We enrolled 12 participants, including 8 males and 4 females, in this study.

This study is a single-arm, open-label, prospective study and conducted at Kanazawa Medical University Hospital. Subjects were treated for 8 weeks with 2 capsules of RWE (containing $9.6 \mathrm{mg}$ resveratrol and $68 \mathrm{mg}$ polyphenols per capsule) twice daily for a total of $19.2 \mathrm{mg}$ resveratrol and $136 \mathrm{mg}$ polyphenols per day. During the study period, participants were instructed to abstain from supplements and foods suspected to contain polyphenols in significant amounts and the adherence for them was confirmed every visit. Moreover, the importance of maintaining their normal way of life was underscored. Compliance, defined as the proportion of capsules ingested relative to the intended number, was calculated when participants returned the remaining capsules during the final visit.

\subsection{Overall Visits and Interventions}

Examinations were performed at baseline and 4 and 8 weeks after supplementation with RWE, with the same equipment and by the same physicians. When completing the physical examination, 
including routine clinical biochemistry data at baseline, capsules were provided and participants were instructed to initiate capsule consumption from the evening and twice daily. At week 4, potential adverse events were recorded and fasting blood samples were taken for safety purposes. In addition, participants visited the hospital on the examination day in the morning after overnight fasting at week 8 and then blood samples were collected.

\subsection{Ethical Approval}

Participants were given detailed explanations of the study protocol. Informed consent was obtained from each participant. The study protocol was approved by the Regional Committee on Health Research Ethics and the Ethical Committee of Kanazawa Medical University (IRB No. M229, Uchinada, Ishikawa, Japan) and conformed to the ethical principles set forth in the Declaration of Helsinki.

\subsection{General Measurements}

Body weight (BW) and body composition were measured using In Body ${ }^{\circledR}$ (Biospace Japan, Inc., Tokyo, Japan) with the participants being lightly clothed; the participants urinated during the 30 min prior to the In Body ${ }^{\circledR}$ assessment [21]. In addition, blood pressure (BP) and heart rate (HR) were measured in a sitting position after resting for 5 min [21]. Routine biochemistry and physical examinations were performed at screening to investigate the presence of exclusion criteria.

\subsection{Blood Sample Analysis}

Routine biochemistry (creatinine (Cr), uric acid (UA), aspartate aminotransferase (AST), alanine transaminase (ALT) and $\gamma$-glutamyl transpeptidase $(\gamma$-GTP)) parameters were analyzed continuously throughout the study at the Department of Clinical Biochemistry of Kanazawa Medical University Hospital using standard methods [21]. HbA1c and glycated albumin were measured using an automated analyzer, HLC-723 ${ }^{\circledR}$ G11 (TOSHO CO., LTD., Tokyo, Japan) [21]. Serum low-density lipoprotein-cholesterol (LDL-C) and high-density lipoprotein-cholesterol (HDL-C) levels were measured using enzymatic methods (QUALIGENT ${ }^{\circledR}$ HDL-C and QUALIGENT ${ }^{\circledR}$ LDL-C, SEKISUI MEDICAL. CO., LTD., Tokyo, Japan) [21]. Serum triglyceride (TG) levels were measured using enzymatic assays (Kyowa Medex, Co., Ltd., Tokyo, Japan) [21]. Free fatty acids (FFAs) were measured by a commercially available kit (Wako Chemicals, Neuss, Germany). Plasma glucose was measured in duplicate immediately after sampling on a YSI 2300 Stat Plus (YSI, Inc., Yellow Springs, OH, USA) [21]. Insulin was analyzed using a time-resolved immunofluorometric assay (AutoDELFIA Insulin kit, catalog no. B080-101, PerkinElmer, Turku, Finland) [21]. Homeostasis model assessment-insulin resistance (HOMA-IR) was calculated by the formula-fasting serum insulin $(\mu \mathrm{U} / \mathrm{mL}) /$ fasting plasma glucose (mg/dL)/405. Serum interleukin-6 (IL-6) was measured by Human IL-6 CLEIA (Chemiluminescent Enzyme Immuno Assay) Fujirebio (Tokyo, Japan) and high-sensitivity C-reactive protein (hsCRP) was measured by a nephelometry method using N-Latex CRPII (Siemens Healthineers, Tokyo, Japan) [21].

\subsection{Sirt1 mRNA Expression in Isolated Peripheral Blood Mononuclear Cells (PBMNCs)}

PBMNCs were collected from $20 \mathrm{~mL}$ of heparinized blood at the beginning and after 8 weeks of the study and isolated using Histopaque-1077 (Sigma-Aldrich, St. Louis, MO, USA), as previously described [22]. PBMNCs were washed three times with phosphate-buffered saline (PBS) (-) and suspended in TRIzol reagent (Thermo Fisher Scientific, Waltham, MA, USA) for quantitative real-time PCR. Total RNA was isolated from isolated PBMNCs, cDNA synthesis and quantitative real-time PCR were performed as previously described [22]. TaqMan probes for Sirt1 were purchased from Thermo Fisher Scientific (Waltham, MA, USA). The analytical data were adjusted to the level of $18 S$ mRNA expression as an internal control. 


\subsection{THP-1 Cell Culture}

Human monocytes (THP-1 cells) obtained from ATCC were cultured in RPMI medium with 10\% fetal calf serum [23]. After $16 \mathrm{~h}$ of serum starvation, THP-1 cells were treated with RWE 166, 332 and $3320 \mathrm{ng} / \mathrm{mL}$ (including 68, 136 or $1360 \mathrm{ng} / \mathrm{mL}$ polyphenols and 9.6, 19.2 and $192 \mathrm{ng} / \mathrm{mL}$ resveratrol, respectively) or Dimethyl sulfoxide (DEMSO) as a control for $24 \mathrm{~h}$. Western blotting was performed using antibodies against Sirt1 (1:1000), phosphor(p)-AMPK $\alpha$ (Thr 172) (1:1000), AMPK $\alpha$ (1:1000) and $\beta$-actin (1:1000), as previously described [23]. The anti-rabbit polyclonal p62 antibody (PM045) was obtained from Medical \& Biological Laboratories (Nagoya, Japan). Anti-phospho (p)-AMPK $\alpha$ (Thr 172), AMPK $\alpha$ and $\beta$-actin antibodies were obtained from Cell Signaling Technology Inc. (Danvers, MA, USA) and anti-Sirt1 antibodies were obtained from Millipore (Bedford, MA, USA).

\subsection{Statistical Analysis}

Data are presented as the means \pm the standard deviation (SD) unless otherwise indicated. The results obtained at baseline and after 8 weeks of RWE supplementation, as well as changes within a group, were compared using a paired $t$-test. One-way ANOVA followed by Tukey's multiple comparison test was used to determine the significance of pairwise differences among three or more groups. The correlation of two variables was analyzed by a single linear regression analysis as a Pearson correlation coefficient. Statistical significance was defined as $p<0.05$ and statistical analyses were performed using StatMate5.

\section{Results}

\subsection{Characteristics at Baseline and after Supplementation with RWE for 8 Weeks}

The physical characteristics of the participants are shown in Table 1. BW and body mass index (BMI) were not significantly different between the baseline and the end of supplementation with RWE. Body composition, including fat mass, \%fat and skeletal fat, showed no significant change between baseline and at 8 weeks of RWE supplementation. Systolic and diastolic BP and HR also showed no change between baseline and after supplementation with RWE. Fasting plasma glucose and serum insulin levels showed no significant change between baseline and the end of RWE supplementation (Table 2). However, HOMA-IR was significantly decreased after supplementation with RWE compared to the baseline. Additionally, the levels of serum TG and LDL-C were significantly decreased and serum HDL-C and FFA levels showed no differences after supplementation with RWE compared to those at baseline. Among the inflammatory markers, serum hsCRP levels were not changed; however, serum IL-6 levels showed significant decreases after 8 weeks of supplementation with RWE from baseline (Table 2). Liver function tests, such as AST, ALT and $\gamma$-GTP and kidney function tests, such as serum creatinine and uric acid, exhibited no significant change between baseline and the end of supplementation with RWE.

Table 1. Characteristics of participants at baseline and after supplementation with red wine extract.

\begin{tabular}{cccc}
\hline & 0 Week & 8 Weeks & $p$ Value \\
\hline Age & $47.5 \pm 11.3$ & & \\
Male:female & $8: 4$ & & \\
Body weight $(\mathrm{kg})$ & $66.6 \pm 16.4$ & $66.0 \pm 16.1$ & 0.282 \\
Body mass index $\left(\mathrm{kg} / \mathrm{m}^{2}\right)$ & $23.3 \pm 3.8$ & $23.1 \pm 3.7$ & 0.278 \\
Systolic blood pressure $(\mathrm{mmHg})$ & $118.8 \pm 13.5$ & $119.7 \pm 13.3$ & 0.658 \\
Diastolic blood pressure $(\mathrm{mmHg})$ & $71.5 \pm 10.4$ & $73.3 \pm 13.0$ & 0.580 \\
Heart rate $(/ \mathrm{min})$ & $71 \pm 8.7$ & $71.4 \pm 5.2$ & 0.860 \\
Fat mass $(\mathrm{kg})$ & $18.8 \pm 8.8$ & $17.8 \pm 8.4$ & 0.067 \\
\%fat & $25.7 \pm 9.3$ & $24.1 \pm 7.0$ & 0.255 \\
Skeletal muscle mass $(\mathrm{kg})$ & $26.1 \pm 6.4$ & $26.5 \pm 6.8$ & 0.369 \\
\hline
\end{tabular}


Table 2. Laboratory data of participants at baseline and after supplementation with red wine extract.

\begin{tabular}{cccc}
\hline & 0 Week & $\mathbf{8}$ Weeks & $p$ Value \\
\hline Fasting plasma glucose $(\mathrm{mg} / \mathrm{dL})$ & $95.6 \pm 8.2$ & $89.6 \pm 9.3$ & 0.100 \\
Fasting serum insulin $(\mu \mathrm{U} / \mathrm{mL})$ & $7.06 \pm 5.49$ & $4.88 \pm 3.88$ & 0.063 \\
HOMA-IR & $1.71 \pm 1.38$ & $1.13 \pm 1.03$ & 0.046 \\
HbA1c $(\%)$ & $5.2 \pm 0.5$ & $5.2 \pm 0.4$ & 0.135 \\
Glycated albumin $(\%)$ & $13.8 \pm 1.2$ & $13.8 \pm 1.1$ & 0.431 \\
LDL-C $(\mathrm{mg} / \mathrm{dL})$ & $119.7 \pm 21.0$ & $114.7 \pm 19.6$ & 0.013 \\
HDL-C $(\mathrm{mg} / \mathrm{dL})$ & $56.0 \pm 19.0$ & $58.0 \pm 11.3$ & 0.097 \\
TG $(\mathrm{mg} / \mathrm{dL})$ & $246.9 \pm 285.6$ & $182.2 \pm 220.5$ & 0.032 \\
log-TG & $2.12 \pm 0.48$ & $2.02 \pm 0.40$ & 0.034 \\
Free fatty acid & $515.0 \pm 309.8$ & $549.5 \pm 177.6$ & 0.688 \\
$\log$ free fatty acid & $2.62 \pm 0.30$ & $2.72 \pm 0.16$ & 0.305 \\
IL-6 $(\mathrm{ng} / \mathrm{mL})$ & $1.8 \pm 0.8$ & $1.4 \pm 0.6$ & 0.019 \\
hsCRP $(\mathrm{mg} / \mathrm{dL})$ & $1049.7 \pm 1620.2$ & $1158.3 \pm 1638.6$ & 0.400 \\
log-hsCRP & $2.70 \pm 0.52$ & $2.73 \pm 0.58$ & 0.666 \\
AST $(\mathrm{IU} / \mathrm{mL})$ & $21.3 \pm 7.3$ & $21.3 \pm 7.4$ & 0.352 \\
ALT $(\mathrm{IU} / \mathrm{mL})$ & $17.0 \pm 18.7$ & $20.0 \pm 20.8$ & 1.000 \\
$\gamma$-GTP $(\mathrm{IU} / \mathrm{mL})$ & $22.3 \pm 71.1$ & $24.0 \pm 59.2$ & 0.435 \\
Cr $(\mathrm{mg} / \mathrm{dL})$ & $0.72 \pm 0.16$ & $0.69 \pm 0.15$ & 0.054 \\
Uric acid $(\mathrm{mg} / \mathrm{dL})$ & $6.1 \pm 2.2$ & $6.1 \pm 2.0$ & 0.574 \\
\hline
\end{tabular}

HOMA-IR: homeostasis model assessment-insulin resistance, LDL-C: low-density lipoprotein-cholesterol, HDL-C: high-density lipoprotein-cholesterol, TG: triglyceride, IL-6: interleukin-6, hsCRP: high-sensitivity C-reactive protein, AST: aspartate aminotransferase, ALT: alanine transaminase, $\gamma$-GTP: $\gamma$-glutamyl transpeptidase, Cr: creatinine, UA: uric acid.

3.2. Change in Sirt1 Expression in Isolated PBMNCs after Supplementation with RWE and the Relationship with the Change in HOMA-IR

Supplementation with RWE for 8 weeks significantly increased Sirt1 mRNA expression in isolated PBMNCs compared to baseline (Figure 1A). Additionally, the relationship between the rate of change in Sirt1 expression in isolated PBMNCs ( $\triangle \%$ Sirt1 mRNA expression) and the rate of change in HOMA-IR $(\triangle \%$ HOMA-IR) from Pearson's correlation coefficient analysis showed a positive correlation $(\mathrm{r}=0.6518$, $p=0.0216$ ) between baseline and the end of RWE supplementation (Figure 1B).

A.

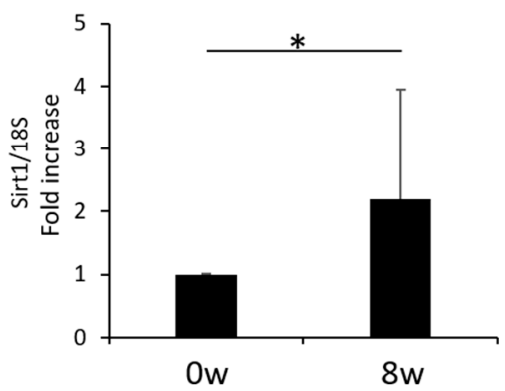

B.

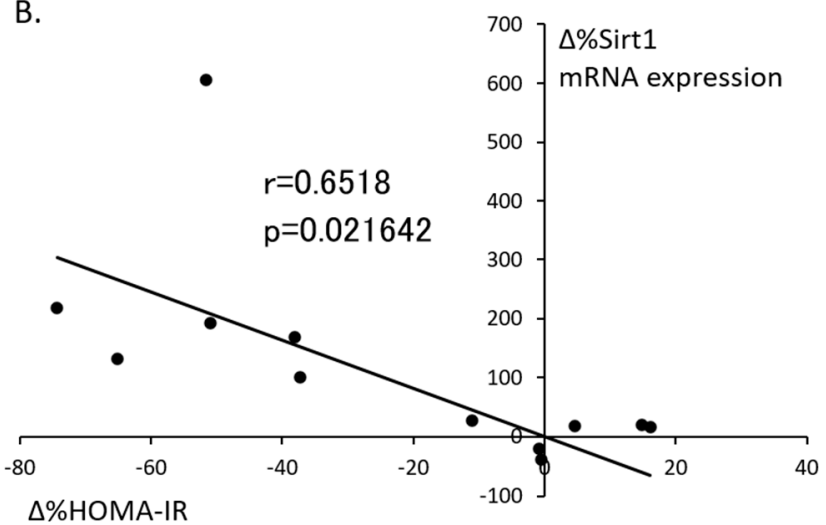

Figure 1. Change in mRNA expression of Sirt1 in PBMNCs after supplementation with red wine extract and the relationship between the change in Sirt1 expression and insulin sensitivity. (A) mRNA expression of Sirt1 normalized to $18 \mathrm{~S}$ levels in isolated PBMNCs $(n=12)$. The data shown are the means \pm the standard deviations. ${ }^{*} p<0.05$ vs. the indicated groups. (B) The relationship between the rate of change in Sirt1 expression in isolated PBMNCs ( $\triangle$ \%Sirt1 mRNA expression) and the rate of change in HOMA-IR ( $\triangle \%$ HOMA-IR) from Pearson's correlation coefficient analysis $(n=12)$. PBMNCs: peripheral blood mononuclear cells, HOMA-IR: homeostasis model assessment-insulin resistance. 


\subsection{RWE Increased Sirt1 and p-AMPK Expression in Cultured THP-1 Cells}

We evaluated whether RWE induced Sirt1 and p-AMPK expression in cultured human THP-1 cells. The administration of RWE at 166, 332 and $3320 \mathrm{ng} / \mathrm{mL}$ (including 68, 136 or $1360 \mathrm{ng} / \mathrm{mL}$ polyphenols and 9.6, 19.2 and $192 \mathrm{ng} / \mathrm{mL}$ resveratrol) in cultured THP-1 cells for $24 \mathrm{~h}$ significantly increased both Sirt1 and p-AMPK expression (Figure 2A-C). In addition, we confirmed that those RWE concentrations were non-toxic to cultured THP-1 cells by (data not shown).

A.

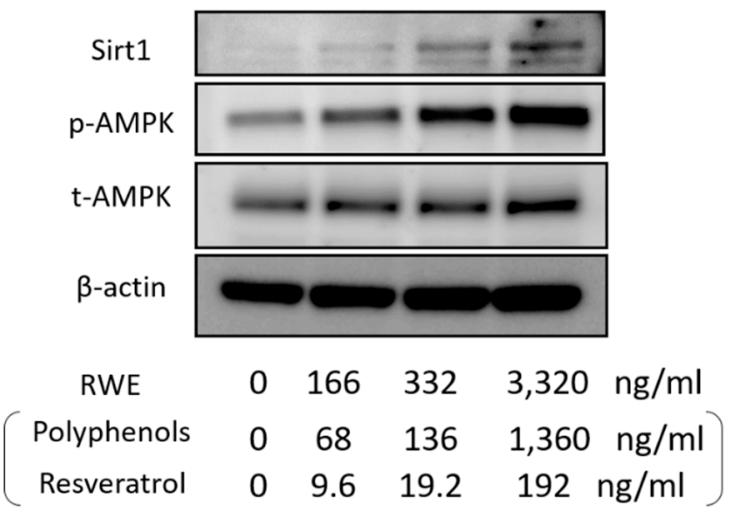

B.

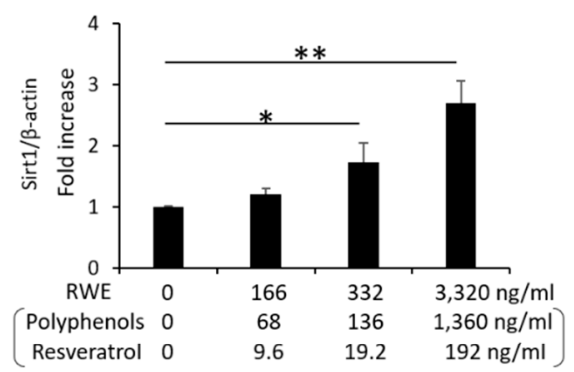

C.

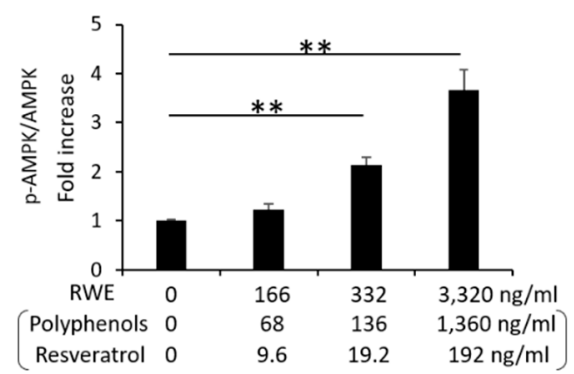

Figure 2. Change in Sirt1 and p-AMPK expression by the administration of red wine extract in cultured THP-1 cells. (A) Representative western blots of Sirt1, p-AMPK, AMPK and $\beta$-actin in cultured THP-1 cells $(n=4)$. (B) Quantitative ratios of Sirt1 to $\beta$-actin $(n=4)$. (C) Quantitative ratios of p-AMPK to $\operatorname{AMPK}(n=4)$. The data shown are the means \pm the standard deviations. ${ }^{*} p<0.05,{ }^{* *} p<0.01$ vs. the indicated groups. AMPK: AMP-activated kinase, RWE: red wine extract.

\section{Discussion}

In this study, we demonstrated that supplementation with RWE for 8 weeks significantly increased insulin sensitivity, which was evaluated by HOMA-IR in humans. Additionally, after supplementation with RWE, serum IL-6 concentration was significantly reduced and showed a decrease in the levels of LDL-C and TG. Moreover, RWE supplementation enhanced Sirt1 expression in isolated PBMNCs, which was associated with an increase in insulin sensitivity.

Previous clinical evidence suggests that red wine consumption exerts beneficial effects on glucose metabolism, including insulin sensitivity. Da Luz et al. showed that regular red wine drinkers (at least one glass of red wine 4-5 days/week for 5 years) have lower glucose levels and a lower occurrence of diabetes than abstainers [24]. Additionally, Napoli et al. demonstrated that red wine consumption ( $360 \mathrm{~mL} /$ day) for 2 weeks markedly improved insulin resistance in patients with T2DM compared to the control group [25]. Chiva-Blanch et al. also compared the effect of moderate consumption of red wine (30 g alcohol/day), dealcoholized red wine and gin on glucose metabolism in 67 men with high cardiovascular disease for 4 weeks [26]. Red wine and dealcoholized red wine but not gin exhibited decreases in plasma insulin levels and HOMA-IR [26]. In this study, we also demonstrated that the values of HOMA-IR were significantly reduced after the administration of RWE containing $136 \mathrm{mg}$ polyphenols per day for 8 weeks in nondiabetic humans.

Since red wine is rich in polyphenolic compounds, including flavonoids (anthocyanins, tannins and catechin) and nonflavonoids (stilbenes such as resveratrol, tyrosol and hydroxytyrosol) [9], the beneficial 
effects of red wine are thought to be exerted through polyphenols. Among the polyphenols, resveratrol has been one of the most extensively studied as a critical constituent that contributes to the health benefits of red wine. Previous studies demonstrated that resveratrol might play potential therapeutic roles in cardiometabolic health through multiple mechanisms, such as anti-inflammatory, antioxidant and anti-diabetic effects, which are mediated by the activation of Sirt1, estrogen receptor (ER) signaling, nuclear factor-erythroid-derived 2-related factor-2 (Nrf2) or AMPK [20,27-29]. Several reports showed that catechin, epicatechin, quercetin and anthocyanin also can activate Sirt1 or AMPK [30-33], however, the number of reports is so few, compared to those of resveratrol. In this study, we focused on Sirt1, which is an important regulator of a wide variety of cellular processes, including glucose/lipid metabolism and anti-inflammation, via the deacetylation of many substrates [34,35]. Our data showed the increased expression of Sirt1 in PBMNCs after supplementation with RWE including $19.2 \mathrm{mg}$ resveratrol. Additionally, the levels of Sirt1 expression in PBMNCs had a positive relationship with insulin sensitivity, which was evaluated by HOMA-IR. Additionally, serum IL-6 was reduced after the administration of RWE including resveratrol. A previous report showed that decreased Sirt1 expression levels in circulating monocytes are correlated with insulin resistance in humans [36]. Moreover, Gillum et al. reported that Sirt1 expression was reduced in adipose tissues of obese males with insulin resistance and mRNA expression of CD14, a macrophage marker, in adipose tissue is negatively correlated with Sirt1 expression [37]. Chronic low-grade tissue inflammation is an important etiological component of insulin resistance [38]. Elevated levels of proinflammatory cytokines, such as IL-6, in the blood have been detected in individuals with insulin resistance. The activation of monocytes/macrophages in the circulation and adipose tissue has been demonstrated to lead to the release of various inflammatory mediators. Sirt1 may contribute to the negative regulation of inflammation in several tissues or cells, including monocytes/macrophages, through the deacetylation of NF-kB (p65 subunit) [39-41]. Therefore, the effect of RWE including resveratrol on insulin resistance and inflammation may be associated with increased Sirt1 expression in PBMNCs. However, we could not show the levels of acetylated NF-KB (p65) in mononuclear cells or the relationship between Sirt1 expression and serum IL-6 values.

In addition to reducing inflammation, previous reports showed that Sirt1 may positively regulate insulin signaling by interacting with tyrosine phosphatase $1 \mathrm{~B}$, insulin receptor substrate or phosphoinositide 3-kinase in insulin-sensitive tissues such as skeletal muscle [42-44]. Timmers et al. also reported that resveratrol supplementation (150 mg/day) for 30 days in obese humans increased insulin sensitivity, improved muscle mitochondrial respiration and activated Sirt1 and AMPK in skeletal muscle [45]. Additionally, Liu et al. reported that resveratrol inhibited inflammation and ameliorated insulin-resistant endothelial dysfunction through AMPK and Sirt1 [46]. In this study, we demonstrated that the administration of RWE including resveratrol increased the expression of Sirt1 and p-AMPK in cultured THP-1 cells. However, we could not evaluate Sirt1 expression levels or inflammation in other tissues/cells, such as skeletal muscle, adipose tissue or endothelial cells.

On the other hand, other reports indicate that resveratrol has no effects on insulin sensitivity. Yoshino et al. demonstrated that oral resveratrol $(75 \mathrm{mg} /$ day) supplementation in nonobese and postmenopausal women with normal glucose tolerance did not improve metabolic function, including insulin sensitivity [47]. Moreover, Poulsen et al. reported that resveratrol (500 mg/day) supplementation in obese men had no effect on insulin sensitivity [48]. Thus, the efficacy of resveratrol for insulin sensitivity is controversial in humans. Therefore, the beneficial effects of RWE may be attributed to the overall mix of all of its components and not to a specific action of one, such as resveratrol.

Sirt1 regulates lipid metabolism through the modulation of sterol regulatory element-binding protein (SREBP)-1C activity, liver $X$-receptor (LXR) and farnesoid $X$ receptor (FXR) via deacetylation of those molecules [49-51]. Therefore, in this study, RWE including resveratrol might contribute to deceased levels of LDL-C and TG through Sirt1 activation, in addition to increased insulin sensitivity.

There are several limitations in this study. First, this study is a single-arm, open-label study with small sample size and occurred over a short time period. Second, participants in this study are 
individuals who are interested in health and the supplements. Therefore, the bias on the results in this study cannot be eliminated. However, the results from in vitro experiments showing that RWE increases Sirt1 expression can support the results in PBMNCs of this study. Third, we could not measure the concentration of polyphenols, including resveratrol, in circulation. Fourth, we evaluated Sirt1 expression in only PBMNCs, not in other tissues/cells. Lastly, we evaluated insulin resistance only by the calculation of HOMA-IR, although the gold standard method for assessment of insulin sensitivity is a hyperinsulinemic-euglycemic clamp study.

\section{Conclusions}

Supplementation with RWE improved metabolism, such as insulin sensitivity, lipid profile and inflammation, in nondiabetic humans. Additionally, RWE supplementation induced an increase in Sirt1 expression in PBMNCs, which may be associated with an improvement in insulin sensitivity. However, further study including a randomized control trial or a cross over trial will be required to confirm these results.

Supplementary Materials: The following are available online at http://www.mdpi.com/2072-6643/12/10/3108/s1, Figure S1: Analysis of red wine extract by HPLC.

Author Contributions: M.K. and D.K. designed the study, researched and analyzed the data and wrote and edited the manuscript. M.K., Y.O. and D.K. contributed to the research and to the collection and analysis of the data. I.M. contributed to the discussion. M.K. and D.K. are the guarantors of this work. All authors have read and agreed to the published version of the manuscript.

Funding: This research was funded by Boehringer Ingelheim, Mitsubishi Tanabe Pharma, Kyowa Kirin, Taisho Pharmaceutical Co. and Ono Pharmaceutical Co.

Acknowledgments: We thank Yuka Kuroshima and Taeko Suzuki for the collection of participants and technical support for real-time PCR and western blotting.

Conflicts of Interest: The authors declare no conflict of interest.

\section{References}

1. Arnett, D.K.; Blumenthal, R.S.; Albert, M.A.; Buroker, A.B.; Goldberger, Z.D.; Hahn, E.J; Himmelfarb, C.D.; Khera, A.; Lloyd-Jones, D.; McEvoy, J.W.; et al. 2019 ACC/AHA guideline on the primary prevention of cardiovascular disease. Circulation 2019, 140, e596-e646. [CrossRef]

2. Renaud, S.; de Lorgeril, M. Wine, alcohol, platelets, and the French paradox for coronary heart disease. Lancet 1992, 339, 1523-1526. [CrossRef]

3. Castaldo, L.; Narváez, A.; Izzo, L.; Graziani, G.; Gaspari, A.; Minno, G.D.; Ritieni, A. Red wine consumption and cardiovascular health. Molecules 2019, 24, 3626. [CrossRef]

4. Arranz, S.; Chiva-Blanch, G.; Valderas-Martínez, P.; Medina-Remón, A.; Lamuela-Raventós, R.M.; Estruch, R. Wine, beer, alcohol and polyphenols on cardiovascular disease and cancer. Nutrients 2012, 4, 759-781. [CrossRef]

5. Del Bo', C.; Bernardi, S.; Marino, M.; Porrini, M.; Tucci, M.; Guglielmetti, S.; Cherubini, A.; Carrieri, B.; Kirkup, B.; Kroon, P.; et al. Systematic review on polyphenol intake and health outcomes: Is there sufficient evidence to define a health-promoting polyphenol-rich dietary pattern? Nutrients 2019, 11, 1355.

6. Taguchi, C.; Kishimoto, Y.; Fukushima, Y.; Kondo, K.; Yamakawa, M.; Wada, K.; Nagata, C. Dietary intake of total polyphenols and the risk of all-cause and specific-cause mortality in Japanese adults: The Takayama study. Eur. J. Nutr. 2019, 59, 1263-1271. [CrossRef]

7. Tresserra-Rimbau, A.; Rimm, E.B.; Medina-Remón, A.; Martínez-González, M.A.; de la Torre, R.; Corella, D.; Salas-Salvadó, J.; Gómez-Gracia, E.; Lapetra, J.; Arós, F.; et al. PREDIMED study investigators. Inverse association between habitual polyphenol intake and incidence of cardiovascular events in the PREDIMED study. Nutr. Metab. Cardiovasc. Dis. 2014, 24, 639-647. [CrossRef] [PubMed]

8. Adriouch, S.; Lampuré, A.; Nechba, A.; Baudry, J.; Assmann, K.; Kesse-Guyot, E.; Hercberg, S.; Scalbert, A.; Touvier, M.; Fezeu, L.K. Prospective association between total and specific dietary polyphenol intakes and cardiovascular disease risk in the Nutrinet-Sante French cohort. Nutrients 2018, 10, 1587. [CrossRef] 
9. Chiva-Blanch, G.; Badimon, L. Effects of polyphenol intake on metabolic syndrome: Current evidences from human trials. Oxid. Med. Cell Longev. 2017, 2017, 5812401. [CrossRef]

10. Snopek, L.; Mlcek, J.; Sochorova, L.; Baron, M.; Hlavacova, I.; Jurikova, T.; Kizek, R.; Sedlackova, E.; Sochor, J. Contribution of red wine consumption to human health protection. Molecules 2018, 23, 1684. [CrossRef] [PubMed]

11. Botden, I.P.; Oeseburg, H.; Durik, M.; Leijten, F.P.; Van Vark-Van, D.Z.L.C.; Musterd-Bhaggoe, U.M.; Garrelds, I.M.; Seynhaeve, A.L.; Langendonk, J.G.; Sijbrands, E.J.; et al. Red wine extract protects against oxidative-stress-induced endothelial senescence. Clin. Sci. 2012, 123, 499-507. [CrossRef] [PubMed]

12. Leikert, J.F.; Räthel, T.R.; Wohlfart, P.; Cheynier, V.; Vollmar, A.M.; Dirsch, V.M. Red wine polyphenols enhance endothelial nitric oxide synthase expression and subsequent nitric oxide release from endothelial cells. Circulation 2002, 106, 1614-1617. [CrossRef] [PubMed]

13. Fontana, L.; Partridge, L. Promoting health and longevity through diet: From model organisms to humans. Cell 2015, 161, 106-118. [CrossRef] [PubMed]

14. Colman, R.J.; Anderson, R.M.; Johnson, S.C.; Kastman, E.K.; Kosmatka, K.J.; Beasley, T.M.; Allison, D.B.; Cruzen, C.; Simmons, H.A.; Kemnitz, J.W.; et al. Caloric restriction delays disease onset and mortality in rhesus monkeys. Science 2009, 325, 201-204. [CrossRef]

15. Fontana, L.; Meyer, T.E.; Klein, S.; Holloszy, J.O. Long-term calorie restriction is highly effective in reducing the risk for atherosclerosis in humans. Proc. Natl. Acad. Sci. USA 2004, 101, 6659-6663. [CrossRef]

16. Meyer, T.E.; Kovács, S.J.; Ehsani, A.A.; Klein, S.; Holloszy, J.O.; Fontana, L. Long-term caloric restriction ameliorates the decline in diastolic function in humans. J. Am. Coll. Cardiol. 2006, 47, 398-402. [CrossRef]

17. Kraus, W.E.; Bhapkar, M.; Huffman, K.M.; Pieper, C.F.; Krupa Das, S.; Redman, L.M.; Villareal, D.T.; Rochon, J.; Roberts, S.B.; Ravussin, E.; et al. CALERIE Investigators. 2 years of calorie restriction and cardiometabolic risk (CALERIE): Exploraatory outcomes of a multicentre, phase 2, randomised controlled trial. Lancet Diabetes Endocrinol. 2019, 7, 673-683. [CrossRef]

18. Imai, S.; Armstrong, C.M.; Kaeberlein, M.; Guarente, L. Transcriptional silencing and longevity protein Sir2 is an NAD-dependent histone deacetylase. Nature 2000, 403, 795-800. [CrossRef]

19. Cohen, H.Y.; Miller, C.; Bitterman, K.J.; Wall, N.R.; Hekking, B.; Kessler, B.; Howitz, K.T.; Gorospe, M.; de Cabo, R.; Sinclair, D.A. Calorie restriction promotes mammalian cell survival by inducing the SIRT1 deacetylase. Science 2004, 305, 390-392. [CrossRef]

20. Howitz, K.T.; Bitterman, K.J.; Cohen, H.Y.; Lamming, D.W.; Lavu, S.; Wood, J.G.; Zipkin, R.E.; Chung, P.; Kisielewski, A.; Zhang, L.L.; et al. Small molecule activators of Sirtuins extend Saccharomyces cerevisiae lifespan. Nature 2003, 425, 191-196. [CrossRef]

21. Kitada, M.; Ogura, Y.; Maruki-Uchida, H.; Sai, M.; Suzuki, T.; Kanasaki, K.; Hara, Y.; Seto, H.; Kuroshima, Y.; Monno, I.; et al. The effect of piceatannol from passion fruit (Passiflora edulis) seeds on metabolic health in humans. Nutrients 2017, 9, 1142. [CrossRef]

22. Kitada, M.; Kume, S.; Takeda-Watanabe, A.; Tsuda, S.; Kanasaki, K.; Koya, D. Calorie restriction in overweight males ameliorates obesity-related metabolic alterations and cellular adaptations through anti-aging effects, possibly including AMPK and SIRT1 activation. Biochim. Biophys. Acta 2013, 1830, 4820-4827. [CrossRef]

23. Takeda-Watanabe, A.; Kitada, M.; Kanasaki, K.; Koya, D. SIRT1 inactivation induces inflammation through the dysregulation of autophagy in human THP-1 cells. Biochem. Biophys. Res. Commun. 2012, 427, 191-196. [CrossRef]

24. Luz, P.L.; Coimbra, S.; Favarato, D.; Albuquerque, C.; Mochiduky, R.I.; Rochitte, C.E.; Hojaij, E.; Gonsalves, C.R.; Laurindo, F.R. Coronary artery plaque burden and calcium scores in healthy men adhering to long-term wine drinking or alcohol abstinence. Braz. J. Med. Biol. Res. 2014, 47, 697-705. [CrossRef]

25. Napoli, R.; Cozzolino, D.; Guardasole, V.; Angelini, V.; Zarra, E.; Matarazzo, M.; Cittadini, A.; Saccà, L.; Torella, R. Red wine consumption improves insulin resistance but not endothelial function in type 2 diabetic patients. Metabolism 2005, 54, 306-313. [CrossRef]

26. Chiva-Blanch, G.; Urpi-Sarda, M.; Ros, E.; Valderas-Martinez, P.; Casas, R.; Arranz, S.; Guillén, M.; Lamuela-Raventós, R.M.; Llorach, R.; Andres-Lacueva, C.; et al. Effects of red wine polyphenols and alcohol on glucose metabolism and the lipid profile: A randomized clinical trial. Clin. Nutr. 2013, 32, 200-206. [CrossRef]

27. Li, H.; Xia, N.; Förstermann, U. Cardiovascular effects and molecular targets of resveratrol. Nitric Oxide 2012, 26, 102-110. [CrossRef] 
28. Magyar, K.; Halmosi, R.; Palfi, A.; Feher, G.; Czopf, L.; Fulop, A.; Battyany, I.; Sumegi, B.; Toth, K.; Szabados, E. Cardioprotection by resveratrol: A human clinical trial in patients with stable coronary artery disease. Clin. Hemorheol. Microcirc. 2012, 50, 179-187. [CrossRef]

29. Csiszar, A. Anti-inflammatory effects of resveratrol: Possible role in prevention of age-related cardiovascular disease. Ann. NY Acad. Sci. 2011, 1215, 117-122. [CrossRef]

30. Zhao, S.; Zhang, L.; Yang, C.; Li, Z.; Rong, S. Procyanidins and Alzheimer's Disease. Mol. Neurobiol. 2019, 56, 5556-5567. [CrossRef]

31. Leyton, L.; Hott, M.; Acuña, F.; Caroca, J.; Nuñez, M.; Martin, C.; Zambrano, A.; Concha, M.I.; Otth, C. Nutraceutical activators of AMPK/Sirt1 axis inhibit viral production and protect neurons from neurodegenerative events triggered during HSV-1 infection. Virus. Res. 2015, 205, 63-72. [CrossRef]

32. Sayed, A.M.; Hassanein, E.H.M.; Salem, S.H.; Hussein, O.E.; Mahmoud, A.M. Flavonoids-mediated SIRT1 signaling activation in hepatic disorders. Life Sci. 2020, 259, 118173. [CrossRef]

33. De Sousa Moraes, L.F.; Sun, X.; Peluzio, M.D.C.G.; Zhu, M.J. Anthocyanins/anthocyanidins and colorectal cancer: What is behind the scenes? Crit. Rev. Food Sci. Nutr. 2019, 59, 59-71. [CrossRef]

34. Kitada, M.; Ogura, Y.; Monno, I.; Koya, D. Sirtuins and type 2 diabetes: Role in inflammation, oxidative stress, and mitochondrial function. Front. Endocrinol. 2019, 10, 187. [CrossRef]

35. Kitada, M.; Kume, S.; Kanasaki, K.; Takeda-Watanabe, A.; Koya, D. Sirtuins as possible drug targets in type 2 diabetes. Curr. Drug Targets 2013, 14, 622-636. [CrossRef]

36. De Kreutzenberg, S.V.; Ceolotto, G.; Papparella, I.; Bortoluzzi, A.; Semplicini, A.; Dalla Man, C.; Cobelli, C.; Fadini, G.P.; Avogaro, A. Downregulation of the longevity-associated protein Sirtuin 1 in insulin resistance and metabolic syndrome: Potential biochemical mechanisms. Diabetes 2010, 59, 1006-1015. [CrossRef]

37. Gillum, M.P.; Kotas, M.E.; Erion, D.M.; Kursawe, R.; Chatterjee, P.; Nead, K.T.; Muise, E.S.; Hsiao, J.J.; Frederick, D.W.; Yonemitsu, S.; et al. SirT1 regulates adipose tissue inflammation. Diabetes 2011, 60, 3235-3245. [CrossRef]

38. Hotamisligil, G.S.; Arner, P.; Caro, J.F.; Atkinson, R.L.; Spiegelman, B.M. Increased adipose tissue expression of tumor necrosis factor-alpha in human obesity and insulin resistance. J. Clin. Investig. 1995, 95, 2409-2415. [CrossRef]

39. Yoshizaki, T.; Milne, J.C.; Imamura, T.; Schenk, S.; Sonoda, N.; Babendure, J.L.; Lu, J.C.; Smith, J.J.; Jirousek, M.R.; Olefsky, J.M. SIRT1 exerts anti-inflammatory effects and improves insulin sensitivity in adipocytes. Mol. Cell Biol. 2009, 29, 1363-1374. [CrossRef]

40. Schug, T.T.; Xu, Q.; Gao, H.; Peres-da-Silva, A.; Draper, D.W.; Fessler, M.B.; Purushotham, A.; Li, X. Myeloid deletion of SIRT1 induces Inflammatory signaling in response to environmental stress. Mol. Cell Biol. 2010, 30, 4712-4721. [CrossRef]

41. Yoshizaki, T.; Schenk, S.; Imamura, T.; Babendure, J.L.; Sonoda, N.; Bae, E.J.; Oh, D.Y.; Lu, M.; Milne, J.C.; Westphal, C.; et al. SIRT1 inhibits inflammatory pathways in macrophages and modulates insulin sensitivity. Am. J. Physiol. Endocrinol. Metab. 2010, 298, E419-E428. [CrossRef] [PubMed]

42. Sun, C.; Zhang, F.; Ge, X.; Yan, T.; Chen, X.; Shi, X.; Zhai, Q. SIRT1 improves insulin sensitivity under insulin-resistant conditions by repressing PTP1B. Cell Metab. 2007, 6, 307-319. [CrossRef] [PubMed]

43. Zhang, J. The direct involvement of SirT1 in insulin-induced insulin receptor substrate-2 tyrosine phosphorylation. J. Biol. Chem. 2007, 282, 34356-34364. [CrossRef]

44. Fröjdö, S.; Durand, C.; Molin, L.; Carey, A.L.; El-Osta, A.; Kingwell, B.A.; Febbraio, M.A.; Solari, F.; Vidal, H.; Pirola, L. Phosphoinositide 3-kinase as a novel functional target for the regulation of the insulin signaling pathway by SIRT1. Mol. Cell Endocrinol. 2011, 335, 166-176. [CrossRef] [PubMed]

45. Timmers, S.; Konings, E.; Bilet, L.; Houtkooper, R.H.; van de Weijer, T.; Goossens, G.H.; Hoeks, J.; van der Krieken, S.; Ryu, D.; Kersten, S.; et al. Calorie restriction-like effects of 30 days of resveratrol supplementation on energy metabolism and metabolic profile in obese humans. Cell Metab. 2011, 14, 612-622. [CrossRef] [PubMed]

46. Liu, Z.; Jiang, C.; Zhang, J.; Liu, B.; Du, Q. Resveratrol inhibits inflammation and ameliorates insulin resistant endothelial dysfunction via regulation of AMP-activated protein kinase and Sirtuin 1 activities. J. Diabetes 2016, 8, 324-335. [CrossRef] [PubMed]

47. Yoshino, J.; Conte, C.; Fontana, L.; Mittendorfer, B.; Imai, S.; Schechtman, K.B.; Gu, C.; Kunz, I.; Rossi Fanelli, F.; Patterson, B.W.; et al. Resveratrol supplementation does not improve metabolic function in nonobese women with normal glucose tolerance. Cell Metab. 2012, 16, 658-664. [CrossRef] 
48. Poulsen, M.M.; Vestergaard, P.F.; Clasen, B.F.; Radko, Y.; Christensen, L.P.; Stødkilde-Jørgensen, H.; Møller, N.; Jessen, N.; Pedersen, S.B.; Jørgensen, J.O. High-dose resveratrol supplementation in obese men: An investigator-initiated, randomized, placebo-controlled clinical trial of substrate metabolism, insulin sensitivity, and body composition. Diabetes 2013, 62, 1186-1195. [CrossRef]

49. Ponugoti, B.; Kim, D.H.; Xiao, Z.; Smith, Z.; Miao, J.; Zang, M.; Wu, S.Y.; Chiang, C.M.; Veenstra, T.D.; Kemper, J.K. SIRT1 deacetylates and inhibits SREBP-1C activity in regulation of hepatic lipid metabolism. J. Biol. Chem. 2010, 285, 33959-33970. [CrossRef]

50. Li, X.; Zhang, S.; Blander, G.; Tse, J.G.; Krieger, M.; Guarente, L. SIRT1 deacetylates and positively regulates the nuclear receptor LXR. Mol. Cell 2007, 28, 91-106. [CrossRef]

51. Kemper, J.K.; Xiao, Z.; Ponugoti, B.; Miao, J.; Fang, S.; Kanamaluru, D.; Tsang, S.; Wu, S.Y.; Chiang, C.M.; Veenstra, T.D. FXR acetylation is normally dynamically regulated by p300 and SIRT1 but constitutively elevated in metabolic disease states. Cell Metab. 2009, 10, 392-404. [CrossRef] [PubMed]

(C) 2020 by the authors. Licensee MDPI, Basel, Switzerland. This article is an open access article distributed under the terms and conditions of the Creative Commons Attribution (CC BY) license (http://creativecommons.org/licenses/by/4.0/). 